\title{
Tuberculosis in Migrants is Among the Challenges of Tuberculosis Control in High-Income Countries
}

\section{Endrias Markos \\ Woldesemayat (1D}

School of Public Health, College of Medicine and Health Sciences, Hawassa University, Hawassa, Ethiopia
Correspondence: Endrias Markos

Woldesemayat

Email endromark@yahoo.com

\begin{abstract}
The incidence of tuberculosis (TB) is high among migrants in high-income countries. The migration process could contribute to the high incidence of TB among them. Achieving TB elimination from these settings will be difficult unless countries address the burden of TB among migrants. The aim of this review was to describe the challenges of international migration on TB control in high-income, low TB incidence countries. Among migrants, there is a high prevalence of risk factors for TB, such as exposure to TB, HIV, malnutrition, substance use, delayed diagnosis, low education, poor health-seeking, the culture, stigma and marginalization. Discriminatory policies of TB care and social barriers such as language, cultural issues and unfriendly health services may also contribute to the high prevalence of TB among them. TB control among migrants in these settings is important as migrants are vulnerable to $\mathrm{TB}$ infection and disease, and implementing $\mathrm{TB}$ care among them is difficult; it is important to reduce the TB burden in migrants and the community at large and the high risk of multidrug-resistant TB (MDR-TB). TB elimination from high-income countries requires acquiring data and analyzing it to measure the burden, having migrant-sensitive health systems, having policy and legal frameworks and multicountry partnerships and conducting research.
\end{abstract}

Keywords: control, high-income country, migrant, TB

\section{Background}

Tuberculosis (TB) is a chronic infectious disease caused by mycobacterium species, which transmits during coughing or sneezing. The main source of infection is patients with smear-positive TB. Any person can be infected with mycobacterium TB and about one-third of the world's people are infected, which indicates the risk of reactivation of TB among them. ${ }^{1}$ Globally TB is a top infectious cause of death. In 2019, there were an estimated 1.4 million TB deaths and an estimated 10 million people fell ill with $\mathrm{TB}^{2} \mathrm{HIV}$ is the strongest risk factor for TB. Close to half a million new cases of multidrug-resistant (MDR-TB) occur every year, ${ }^{2}$ however, only about a quarter of them are reported. ${ }^{3}$

The trend in incidence of TB and death due to TB are reducing since $2000 .^{2,3}$ Control measures of TB since discovery of the disease were use of food and sanatoriums, bacillus discovery, development of anti-TB medications, Directly Observed Treatment Short course (DOTS) and conducting research. ${ }^{4}$ Currently implemented methods for prevention and controlling of TB includes DOTS; contact tracing; vaccination; infection control measures in areas such as refugee camps, hospitals or work places and prisons; surveillance; environmental control measures such as ventilation, airflows of TB source; wearing of protective equipment; respiratory hygiene and cough 
ethics; and pasteurizing milk. ${ }^{5}$ However, addressing TB care among marginalized group of people such as migrants mostly is not properly implemented. This may affect the global targets of TB control, especially elimination of TB from low TB incidence countries. The aim of this review was to describe challenges related to international migration on TB control in high-income, low TB incidence countries.

In 2018, at the United Nations (UN) General Assembly Meeting on TB in New York City, world leaders endorsed the UN Political Declaration on TB "United to End Tuberculosis" an Urgent Global Response to a Global Epidemic. ${ }^{6}$ The vision of "United to End Tuberculosis" is a world free of TB, that is, having zero deaths or disease or suffering which results in elimination. The goal of the strategy is to end the global TB epidemic. Targets stated for 2035 are reduction by $95 \%$ in TB deaths, $90 \%$ TB incidence and no affected families facing catastrophic costs due to TB. ${ }^{6,7}$

Principles recommended in the End TB strategy are applying DOTS, government stewardship and accountability, monitoring and evaluation, strong coalition with civil society organizations and communities, protection and promotion of human rights, ethics and equity and adapting the strategy and targets at country level, with global collaboration. ${ }^{6}$ Addressing proper TB care among migrants is related to protection and promotion of the human rights, ethics and equity components in the principles of the End TB strategy. Pillars of the End TB strategy which applies for migrants too are integrated, patient-centered care and prevention, having bold policies and supportive systems and intensified research and innovations. ${ }^{6}$

\section{Migration}

Migration is the movement of people, either across an international border or within a state. Based on this migrants can be classified as internal migrants and international migrants. Internal migrants are people who travel for education and for economic improvement within their own country or they are internally displaced people within a country as a result of natural or manmade disasters. ${ }^{8}$ International migrants are people who change their usual place of residence from one country to another. ${ }^{8}$ Some distinct migration periods have taken place since the $16^{\text {th }}$ century. These include migration within Europe, Africa and Asia $\left(17^{\text {th }}-18^{\text {th }}\right.$ centuries $)$, permanent settlement in the colonies ( 1500 s to mid- $19^{\text {th }}$ century), slavery (1550 to the end of the $18^{\text {th }}$ century), Post WWII migration (late 1940s to 1960s) and Post 1970 s migration. ${ }^{9}$ The leading desired destination countries among international migrants between 2010 and 2015 were United States, United Kingdom, Saudi Arabia, Canada, France and Germany. ${ }^{10}$

The number of migrants is increasing. Globally, 740 million internal migrants were reported in $2009^{11}$ and an estimated 272 million international migrants are currently present. ${ }^{12}$ The United States had the highest number of international immigrants, with 48 million migrants in 2015. ${ }^{12}$ Numbers of migrants may rise with climate change and ongoing political instabilities of countries. Large numbers of people migrate from countries such as Syria, Yemen, Jordan, Venezuela, Democratic Republic of Congo, South Sudan, and Eritrea. ${ }^{13-18}$ Some of these countries have a high TB burden. Syria, Afghanistan, Iraq and Kosovo were the leading countries in people applying for asylum in the European Union in $2015 .{ }^{19}$ As people migrate, the risk of facing health challenges also increases among them.

Reasons for migration could be push factors such as political unrest, lack of jobs, overcrowding, desertification, presence of famine, poor medical care, loss of wealth and natural disasters in the country of origin. ${ }^{20}$ It could also occur due to pull factors such as seeking for job opportunities or improving living conditions, having relatives or friends already there, better medical care, political and/or religious freedom and security in the receiving countries. ${ }^{20}$

\section{Migrants and Health}

Migration is one of the social determinants of health, ${ }^{21,22}$ and migrants face various health problems related to migration. Though there is a mortality advantage among international migrants in high-income countries, ${ }^{23}$ it has a disadvantage in morbidity. Migration spreads infectious diseases. ${ }^{24,25}$ Stigma and limited access to care appear to be primary drivers of poor HIV outcomes among migrants in high-income countries. ${ }^{26}$ These factors suggest the importance of giving attention to address the health needs of migrants in high-income countries.

As migrants have the right to physical and mental health, addressing the health problems of migrants is important. ${ }^{13-18}$ Healthy migrants contribute to development outcomes of countries by fulfilling the labor needs in highincome countries, increasing economy (by trade and paying taxes) and sending remittances to their country of origin. Migrants' health contributes to the overall public health, since it reduces the risk of communicable disease spread to others. Some migrants migrate to high-income countries having the risk factors of diseases, for example people with 
latent TB. On the other hand, migration of unhealthy people causes spread of infections to citizens in the country that they migrate to. ${ }^{13-18}$ Although infectious diseases among migrants are known to have a negligible impact on European diseases epidemiology, screening programs need to be implemented and adapted to the different stages of the migratory process to better understand the trends and set priorities for action. Appropriate access to care regardless of legal status is crucial to improve the health status of migrants and prevent the spread of contagious diseases. ${ }^{25}$

\section{Migration and TB}

People treated for TB may migrate to other areas. In a tenyear retrospective cohort study, consisting of 2730 smearpositive TB cases, 458 (16\%) eligible TB cases were missed from a survey due to migration to other areas. ${ }^{27}$ Some of these cases might have migrated to low TB incidence areas or to receiving countries which may have their TB epidemiology affected. Various studies reported that people with history of TB treatment may have recurrent $\mathrm{TB} .{ }^{27,28}$ Generally, the incidence of TB is low in highincome countries, however, it is high among specific groups of people such as migrant populations. Migrants in low TB incidence countries may come from high TB burden areas, where they have contracted mycobacterium tuberculosis infections. Migrants have higher risk of TB compared with people born in high-income countries. ${ }^{29}$ Migrating from high TB burden areas, the migration process and other factors could contribute to the increase in risk of developing TB among them.

Migrant people face greater challenges related to TB. At the origin of migration their health status, the health systems, socioeconomic conditions, famines and political conflicts could adversely affect TB control among migrants. During transit migrants face challenges related to the journey, violence, abuse, nutrition and proper ventilation. At their destination countries the living and working conditions, socioeconomic factors, housing, jobs, access to health care and other services, low wages, health-seeking behavior, cultures, and deportation could increase the risk of TB among them. The challenges upon return of migrants are return with untreated TB, acquiring MDR-TB or developing complications due to TB and absence of TB care facility at settings in the return countries. ${ }^{21}$ Overall the risk factors could be categorized into individual factors such as low socio-economic status, substance use, poor working conditions; social barriers which include language, anti-immigrant sentiments, lack of awareness of entitlement to health services and economic burden, for example income loss.

Migrants are vulnerable to TB due to discriminatory policies, labor and lack of social protection. Risk factors such as a risk of high exposure to TB, HIV, malnutrition, substance use, delayed diagnosis, low educational status, poor health-seeking behavior, culture, stigma and marginalization are common among migrants. ${ }^{21}$ Social barriers such as language, culture, stigma, unfriendly health services also contribute to the high prevalence of TB among them. Costs incurred on TB affected families of migrants, society, industries that hire migrants and the health systems are other problems. ${ }^{21}$ In 2013, in selected high-income countries, foreign-born people had over half of all TB cases with an incidence rate of 8.7-18.4 times higher than in the local population. ${ }^{30}$ There is little transmission of TB among citizens in high-income countries. However, it is high among migrants coming from TB high burden areas and TB that occurs due to a reactivation of latent tuberculosis infection (LTBI). Economic deprivation and social marginalization could potentiate TB among migrants. ${ }^{30,31}$ Migrants may not get adequate TB care if they develop the disease. If the TB which occurs among migrants is not controlled, patients could serve as a source of infection to other people in the society. Therefore, TB could be considered as one of the public health concerns in high-income countries. ${ }^{32}$

Challenges for TB care in low TB incidence countries is its high prevalence among vulnerable populations such as migrants. The End TB strategy prioritizes marginalized, stigmatized and vulnerable populations. Migrants face health inequities, inadequate social protection, humanrights violations and stigmatization. ${ }^{21}$ These condition favor the occurrence of TB among migrants. The high risk of reactivation TB among migrants and dwindling political commitment are also among the challenges of TB care in these countries. ${ }^{33-37}$ The World Health Organization (WHO) suggests that improving TB care among migrants could be considered as a key public health priority towards elimination of TB. ${ }^{38}$

\section{Emerging Concern in TB and Migration}

An emerging concern in TB and migration is MDR-TB. Factors such as improper use of medications, poor health literacy and poor treatment adherence could contribute to MDR-TB among them. Problems of the health system, forced displacement, malnutrition, overcrowding in 
camps and disruption of health services contribute to MDR-TB. Occupational hazards is another factor; nearly one-third of the TB infections are linked to mining activities of migrants in South Africa due to crowded working conditions. $^{21}$

\section{TB Control Among Migrants}

The main challenges of TB care among migrants incorporate the following issues. Challenges in preventing transmission, challenges in case finding, DOTS and case holding, absence of facilities and recording and reporting. Challenges in monitoring migrants' health include the challenge related to diversity in source data (which has differing definitions and denominators) and the dynamics of modern migration (evolving population dynamics or monitoring the denominator). Health effects of migration may extend beyond the first generation and it can be difficult to access migrant populations. ${ }^{39,40}$

Due to their vulnerability, it is important to control TB among migrants. ${ }^{22}$ Moreover, effective TB control measures among migrants would reduce the burden of TB among the citizens of low TB incidence countries. Migrants have increased risk of developing MDR-TB and transmitting it. Undertaking a follow-up TB care among migrants is difficult. The four main principles to address TB care among migrants are acquiring data and analyzing TB burden, having migrant-sensitive health systems, having policy and legal frameworks and multi-country partnerships. ${ }^{22,39}$

Acquiring data and analyzing TB burden among migrants in high-income countries is one of the principles of TB care. As migrants are marginalized and disadvantaged this intervention helps to build data on migrant types and migration-related variables. Moreover, it helps to study the economic impact of not addressing TB care among migrants, the cost-effectiveness of active TB screening programs and TB funding for migrants. ${ }^{21,39,40}$ Having migrantsensitive health systems is another important issue in addressing TB care among migrants. It incorporates delivering a rights-based health system, including migrants' issues in the national TB programs, establishing cross-border referral systems; contact tracing, empowering migrants and in camp hygiene. ${ }^{39,40}$ Developing and implementing policy and legal frameworks is the other component of addressing TB care among migrants. Reduction of social and health inequality among migrants should be incorporated into concerted actions to meet TB control targets. It includes having a shared solution between health and non- health sectors. Avoiding stigma, discrimination and restrictions is the other area for action. Improving access to TB care and public-private and regional frameworks to address health-care needs are other important interventions. ${ }^{21,39,40}$ Multi-country partnerships is another point of action in addressing TB care among migrants. The partnership should be between governmental, private sectors, civil society, humanitarian and development agencies and donors. It is suggested that migrant-receiving countries should invest in TB programs in migrants' countries of origin and transit so that the migration could be minimized. ${ }^{21,39,40}$ Conducting research on the area could be considered as the core issue in these principles.

In this regard there are activities implemented in some areas. ${ }^{41,42}$ For instance building a European database to gather multi-country evidence on active and latent TB screening for migrants (Italy, Sweden, United Kingdom, the Netherlands) and community based testing of migrants for infectious diseases (COMBATID): impact, acceptability and cost-effectiveness of identifying infectious diseases among migrants in primary care: protocol for an interrupted time series, qualitative and health economic analysis. $^{41,42}$ However, countries such as Greece and Italy face difficulties in the management of migrants and the poor living conditions in the migration centers may increase the spread of TB. ${ }^{43}$

\section{Conclusions}

Migration is an important characteristic which can affect the health of people. Migrants are more vulnerable and face higher challenges related to TB. Migrants in high-income countries may come from low-income countries where the prevalence of TB is high. This and other risk factors could increase the risk of TB among them. Thus, it is important to address TB control among migrants in high-income countries. Implementation of TB care among migrants in these settings could contribute to TB elimination from these countries and the global End TB target. For achieving this political commitment, policy and legal frameworks, cross-border TB care partnerships, active case finding and research are needed. Political commitment and policy and legal frameworks are required also for the interventions in acquiring data and analyzing TB burden, and having migrantsensitive health systems. Implementing these principles could improve access to care and minimize the TB burden among migrants in low TB incidence countries and help in achieving the End TB target. 
As migrants are marginalized and disadvantaged acquiring data and analyzing TB burden among them is one of the key issues of TB care. Building data on migration-related variables, investigating the economic impact of not addressing TB care among migrants and studies on cost-effectiveness of active TB screening programs and TB funding for migrants are required. In development of migrant-sensitive health systems such as a rights-based health system, incorporating migrants' issues in their national TB programs, empowering migrants, promoting camp hygiene, contact tracing and establishing cross-border referral systems are suggested. Policy and legal frameworks development issues in the area of improving access to TB care for migrants; avoiding stigma, discrimination and restrictions for migrants; having shared solutions between health and non-health sectors and public-private and regional frameworks to address the health care needs are required. With regard to multi-country partnerships, having bilateral agreements for TB management between countries or regions; developing a system where migrant-receiving countries invest in TB programs in countries of migrants' origin and transit and having partnerships between governmental, private sectors, civil society, humanitarian and development agencies and donors could be developed.

\section{Abbreviations}

DOTS, Directly Observed Treatment Short course; EU, European Union; HIV, Human Immunodeficiency Virus; LTBI, latent tuberculosis infection; MDR, multidrug resistant; TB, tuberculosis; UN, United Nation; WHO, World Health Organization; WWII, World War II.

\section{Acknowledgments}

The author thanks the following persons for providing comments. Professor Bente Elisabeth Moen, Professor Sven Gudmund Hinderaker, Professor Emeritus Gunnar Aksel Bjune and Professor Jon Øyvind Odland.

\section{Funding}

EMW is an employee of School of Public Health, College of Medicine and Health Sciences, Hawassa University and receives salary from the University. Hawassa University does not have role in the designing, collecting literatures, interpreting, or writing the article.

\section{Disclosure}

The author reports no conflicts of interest in this work.

\section{References}

1. Harries AD, Dye C. Tuberculosis. Ann Trop Med Parasitol. 2006;1000(5-6):415-431.

2. LWHO. Global Tuberculosis Report. Jeneva: World Health Organization; 2020.

3. World Health Organization. Global Tuberculosis Report. Geneva, Switzerlands: World Health Organization; 2018.

4. Daniel T. The history of tuberculosis Past, present, and challenges for the future. In: Schaaf HS, Zumla A, editors. Tuberculosis: A Comprehensive Clinical Reference. Elsevier; 2009:1-7.

5. World Health Organization. Best Practices in Prevention, Control and Care for Drug-Resistant Tuberculosis. Geneva, Switzerland: World Health Organization; 2013.

6. World Health Organization. The End TB Strategy. Geneva, Switzerland: World Health Organization; 2015.

7. World Health Organization. Resolution WHA67/11: Global Strategy and Targets for Tuberculosis Prevention, Care and Control After 2015. Geneva, Switzerlands: World Health Organization; 2014.

8. World Health Organization. World Health Organization 2016. Tuberculosis Control in Migrant Population. Guiding Principles and Proposed Actions. World Health Organization Western Pacific Region; 2016.

9. A history of migration. Avilable from: https://www.striking-women. org/module/migration/history-migration. Accessed June 25, 2021.

10. International Organization for Migration. World Migration Report: International Organization for Migration. The UN Migration agency; 2018.

11. International Organization for Migration. World Migration Report: International Organization for Migration. United Nations Developement Program; 2009.

12. International Organization for Migration. World Migration Report: International Organization for Migration. The UN Migration agency; 2020.

13. International Organization for Migration. International Migration Law: Glossary on Migration. Second ed. Geneva: International Organization for Migration; 2011.

14. United Nations Development Programme. Human Development Report 2009. Overcoming Barriers: Human Mobility and Development. New York: United Nations Development Programme; 2009.

15. United Nations. Trends in International Migrant Stock: Migrants by Age and Sex (United Nations Database, POP/DB/MIG/Stock/ Rev.2013). New York: United Nations Secretariat: United Nations, Department of Economic and Social Affairs, Population Division; 2013.

16. Zimmerman C, Kiss L, Hossain M. Migration and health: a framework for $21^{\text {st }}$ century policy-making. PLoS Med. 2011;8: e1001034. doi:10.1371/journal.pmed.1001034

17. United Nations. Contribution of Migrants to Development: Trade, Investment and Development Linkages. Geneva: United Nations Conference on Trade and Development; 2009.

18. World Bank. Migration and Development Brief 19: Remittances to Developing Countries Will Surpass $\$ 400$ Billion in 2012. Washington DC: World Bank; 2012.

19. BBC; 2019. Available from: https://www.bbc.com/news/world-eur ope-34131911. Accessed June 25, 2021.

20. Bidwell P, Laxmikanth P, Blacklock C, et al. Security and skills: the two key issues in health worker migration. Glob Health Action. 2014;7:24194. eCollection 22014. doi:10.3402/gha.v7.24194

21. International Organization for Migration. Migration and Tuberculosis: A Pressing Issue. Geneva, Switzerland: Migration Health Division, International Organization for Migration; 2021.

22. Dhavan P, Dias HM, Creswell J, Weil D. An overview of tuberculosis and migration. Int $J$ Tuberc Lung Dis. 2017;21(6):610-623. doi:10.5588/ijtld.16.0917 
23. Aldridge RW, Nellums LB, Bartlett S, et al. Global patterns of mortality in international migrants: a systematic review and meta-analysis. Lancet. 2018;392(10164):2553-2566. doi:10.1016/ S0140-6736(18)32781-8

24. World Health Organization. Globalization and Infectious Diseases: A Review of the Linkage. Jeneva, Switzerland: UNDP/World Bank/ WHO Special Programme for Research and Training in Tropical Diseases (TDR); 2004.

25. Castelli F, Sulis G. Migration and infectious diseases. Clin Microbiol Infect. 2017;23(5):283-289. doi:10.1016/j.cmi.2017.03.012

26. Ross J, Cunningham CO, Hanna DB. HIV outcomes among migrants from low-income and middle-income countries living in high-income countries: a review of recent evidence. Curr Opin Infect Dis. 2018;31 (1):25-32. doi:10.1097/QCO.0000000000000415

27. Dangisso MH, Woldesemayat EM, Datiko DG, Lindtjørn B. Longterm outcome of smear-positive tuberculosis patients after initiation and completion of treatment: a ten-year retrospective cohort study. PLoS One. 2018;13(3):e0193396. doi:10.1371/journal.pone.0193396

28. Millet JP, Shaw E, Orcau A, et al. Tuberculosis recurrence after completion treatment in a European city: reinfection or relapse? PLoS One. 2013;8(6)

29. Kristina LK, Troels L, Joergen HP, et al. Tuberculosis incidence among migrants according to migrant status: a cohort study, Denmark, 1993 to 2015. Euro Surveill. 2019;24(44):pii=1900238.

30. Pareek M, Greenaway C, Noori T, Munoz J, Zenner D. The impact of migration on tuberculosis epidemiology and control in high-income countries: a review. BMC Med. 2016;14:48. doi:10.1186/s12916-0160595-5

31. Pereira C, Gomes P, Taveira R, et al. Insights on the Mycobacterium tuberculosis population structure associated with migrants from Portuguese-speaking countries over a three-year period in Greater Lisbon, Portugal: implications at the public health level. Infect Gene Evol. 2019;71:159-165. doi:10.1016/j.meegid.2019.03.025

32. International Organization for Migration. Glossary on Migration. Second ed. Geneva, Swizerland: International Organization for Migration; 2011.

33. Lönnroth K, Castro K, Chakaya JM, et al. Tuberculosis control and elimination 2010-50: cure, care, and social development. Lancet. 2010;375:1814-1829. doi:10.1016/S0140-6736(10)60483-7
34. Lönnroth K, Jaramillo E, Williams BG, Dye C, Raviglione M. Drivers of tuberculosis epidemics: the role of risk factors and social determinants. Social Sci Med. 2009;68:2240-2246. doi:10.1016/j. socscimed.2009.03.041

35. Diel R, Meywald-Walter K, Gottschalk R, Rusch-Gerdes S, Niemann S. Ongoing outbreak of tuberculosis in a low-incidence community: a molecular-epidemiological evaluation. Int $J$ Tuberc Lung Dis. 2004;8:855-861.

36. Kamper-Jørgensen Z, Andersen AB, Kok-Jensen A, Bygbjerg IC, Thomsen VO, Lillebaek T. Characteristics of non-clustered tuberculosis in a low burden country. Tuberculosis (Edinb). 2012;92:226-231. doi:10.1016/j.tube.2012.02.001

37. World Health Organization. Health of Migrants: Report by the Secretariat. Sixty-First World Health Assembly Document A61/12. Geneva: World Health Organization; 2008.

38. World Health Organization. Framework Towards Tuberculosis Elimination in Low-Incidence Countries. Geneva: World Health Organization; 2014.

39. World Health Organization. Health of Migrants: The Way Forward Report of a Global Consultation. Madrid, Spain: World Health Organization; 2010.

40. World Health Organization. Tuberculosis Control in Migrant Populations: Guiding Principles and Proposed Actions. World Health Organization; 2016.

41. Öhda JN, Lönnrotha K, Abubakarc I, et al. Building a European database to gather multi-country evidence on active and latent TB screening for migrants. International Journal of Infectious Diseases. 2019;80:S45-S49. doi:10.1016/j.ijid.2019.02.041

42. Pareek M, Eborall HC, Wobi F, et al. Community based testing of migrants for infectious diseases (COMBATID): impact, acceptability and cost-effectiveness of identifying infectious diseases among migrants in primary care: protocol for an interrupted timeseries, qualitative and health economic analysis. BMJ Open. 2019;9. doi:10.1136/bmjopen-2019-029188

43. Sotgiu G, Dara M, Centis R, et al. Breaking the barriers: migrants and tuberculosis. La Presse Médicale. 2017;46(2):e5-e11. doi:10.1016/j. lpm.2017.01.013
Risk Management and Healthcare Policy

\section{Publish your work in this journal}

Risk Management and Healthcare Policy is an international, peerreviewed, open access journal focusing on all aspects of public health, policy, and preventative measures to promote good health and improve morbidity and mortality in the population. The journal welcomes submitted papers covering original research, basic science, clinical \& epidemiological studies, reviews and evaluations,

\section{Dovepress}

guidelines, expert opinion and commentary, case reports and extended reports. The manuscript management system is completely online and includes a very quick and fair peer-review system, which is all easy to use. Visit http://www.dovepress.com/testimonials.php to read real quotes from published authors. 